\title{
Formal Synthesis of Pseudolaric Acid B
}

\author{
Naoki Mori* (iD) \\ Research Foundation ITSUU Laboratory, C1232 Kanagawa \\ Science Park R \& D Building, 3-2-1 Sakado, Takatsu-ku, \\ Kawasaki, Kanagawa 213-0012, Japan \\ nmori@itsuu.or.jp
}

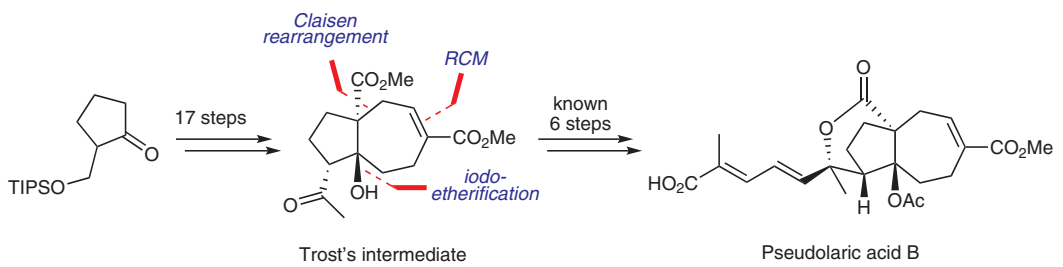

Received: 28.12.2019

Accepted after revision: 02.02.2020

Published online: 18.02 .2020

DOI: 10.1055/s-0039-1690829; Art ID: st-2019-u0701-I

Abstract A formal synthesis of pseudolaric acid B, a diterpene isolated from the root bark of Pseudolarix kaempferi Gordon (Pinaceae), to Trost's synthetic intermediate was achieved in 17 steps from a known ketone. Key features of this synthesis include a Claisen rearrangement and iodoetherification to construct quaternary stereocenters and ringclosing metathesis to form the seven-membered ring.

Key words pseudolaric acid B, total synthesis, diterpenes, cytotoxins, Claisen rearrangement, iodoetherification

More than 20 natural pseudolaric acids, including pseudolaric acids A (1) and B (2), have been isolated from the root bark of Pseudolarix kaempferi Gordon (Pinaceae) (Figure 1). ${ }^{1}$ Among the members of this family, pseudolaric acid B (2) has significant medical potential, exhibiting potent antifungal, antifertility, and cytotoxic activities, even against multidrug-resistant cancer cell lines. These latter activities suggest that $\mathbf{2}$ might function as a potential lead for new anticancer agents. Structurally, pseudolaric acids A (1) and B (2) feature a distinctive tricyclic core with an unusual trans-fused [5-7] ring system. The complicated structures, as well as the important biological properties, of pseudolaric acids have fascinated both biochemists and synthetic chemists. In fact, Mafu et al. ${ }^{2}$ recently identified an enzyme involved in the biosynthetic pathway of $\mathbf{2}$, and two total syntheses of 1 by Chiu and co-workers ${ }^{3}$ [26 steps for (-)-1] and Yang and co-workers ${ }^{4}$ [16 steps for ( \pm )-1 ], and one total synthesis of $\mathbf{2}$ by Trost et al. ${ }^{5}$ [28 steps for (-)-2] have been reported. We previously attempted to improve on the synthesis of $\mathbf{2}$ by using a Dieckmann condensation as the key step to construct its trans-fused core framework. ${ }^{6}$ Here, we describe a formal synthesis of $\mathbf{2}$ by using a new synthetic strategy.

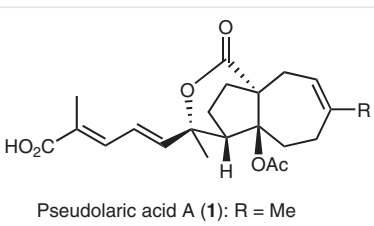

Pseudolaric acid $\mathrm{B}(2): \mathrm{R}=\mathrm{CO}_{2} \mathrm{Me}$

Figure 1 Structures of pseudolaric acids A (1) and B (2)

We previously synthesized model compound $\mathbf{9}$, containing the trans-fused bicyclic core of 2 , in 20 steps, starting from the known compound $\mathbf{3}^{7}$ (Scheme 1a). ${ }^{6}$ However, the yield of the radical coupling reaction $\mathbf{4} \rightarrow \mathbf{5}$ was quite low due to undesirable side reactions; i.e., a 1,6-hydrogen shift to generate compound $\mathbf{6}$, and a direct reduction by $\mathrm{Bu}_{3} \mathrm{SnH}$ to generate compound 7. To overcome these disadvantages, we designed an alternative approach for the synthesis of $\mathbf{2}$ (Scheme 1b). Pseudolaric acid B (2) can be accessed from Trost's intermediate $\mathbf{1 0}$ in six steps; we therefore chose $\mathbf{1 0}$ as our synthetic goal. Based on our retrosynthetic analysis, the seven-membered ring of $\mathbf{1 0}$ might be constructed through a ring-closing metathesis (RCM) reaction of diene 11, obtained by a reductive opening of the tetrahydrofuran ring of the iodo ester 12. Installation of an unsaturated ester side chain onto 12 might be achieved through a radical coupling of iodo alcohol 14 with the allylstannane 13. ${ }^{8}$ We expected that this Keck radical allylation, which proceeds in the absence of $\mathrm{Bu}_{3} \mathrm{SnH}$, would be effective in increasing the yield of the desired product. Compound 14 might be prepared from the known starting material $15,{ }^{9}$ in which a TIPS protecting group replaces the previously employed $\mathrm{Bn}$ group to avoid the presence of troublesome benzylic hydrogens.

Our synthesis commenced with the preparation of aldehyde $\mathbf{2 2}$ (Scheme 2). Methoxycarbonylation of $\mathbf{1 5}$ provided a diastereomeric mixture of esters $\mathbf{1 6}(\mathrm{dr}=2: 1)$, which were 
converted into the enol triflate $\mathbf{1 7}$ in $78 \%$ yield. Because a Stille-type coupling ${ }^{10}$ of $\mathbf{1 7}$ with $\mathrm{Bu}_{3} \mathrm{SnCH}_{2} \mathrm{OPMB}^{11}$ was unsuccessful, we installed a hydroxymethyl group through palladium-catalyzed carboxylation ${ }^{12}$ and subsequent reduction to afford the alcohol $\mathbf{2 0}$ in 65\% yield over two steps. After the formation of a vinyl ether of alcohol $\mathbf{2 0}$, Claisen rearrangement of the resultant product $\mathbf{2 1}$ in refluxing DMF for one hour gave aldehyde $\mathbf{2 2}$ [50\%; quantitative based on recovered starting material (brsm)] in a 3.3:1 diastereomeric ratio, which was consistent with our previous results. ${ }^{6}$ Note that longer reaction times adversely affect the yield of $\mathbf{2 2}$, owing to its decomposition in refluxing DMF (14\% after $6 \mathrm{~h}$ ).

We next sought to prepare diene 11, beginning with the introduction of a hydroxymethyl group onto aldehyde $\mathbf{2 2}$ (Scheme 3). Unfortunately, the addition of $\mathrm{LiCH}_{2} \mathrm{OPMB}$ to 22

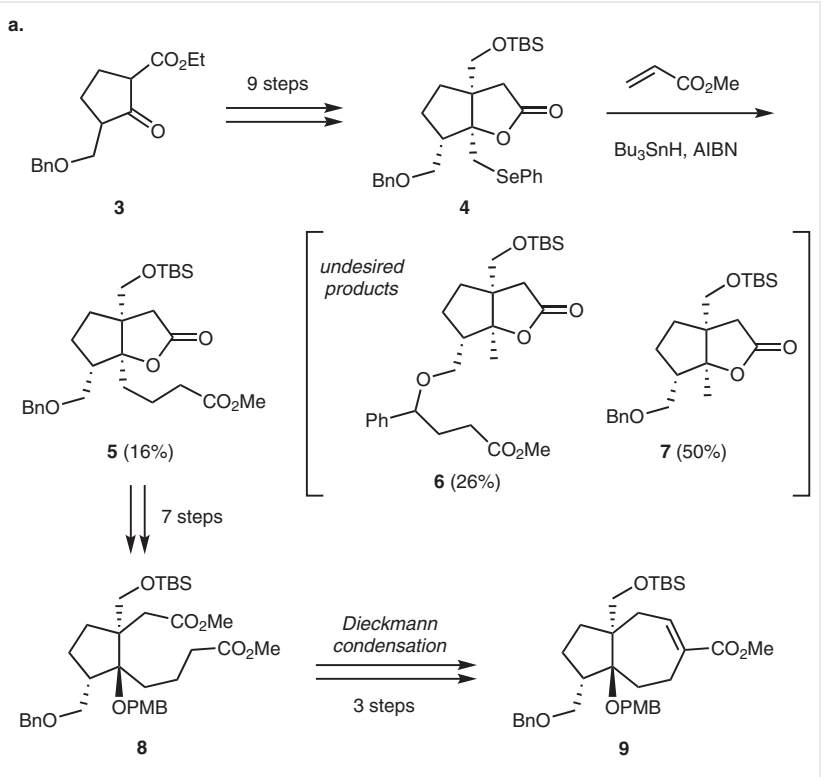

b.
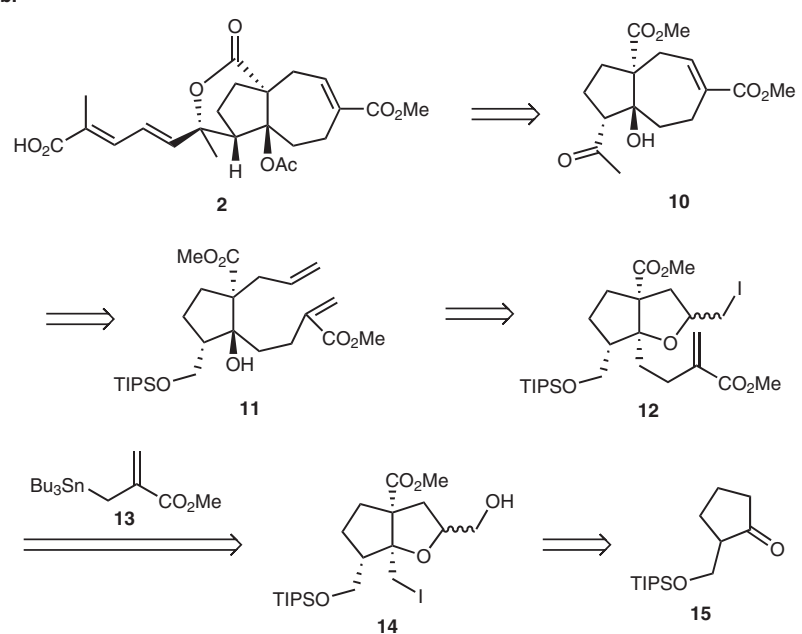

Scheme 1 Our (a) previous work ${ }^{6}$ and (b) current retrosynthetic analysis for pseudolaric acid B (2)
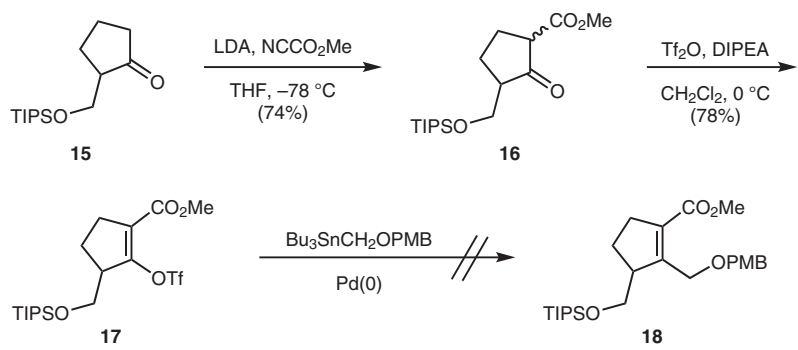

$\mathrm{Ac}_{2} \mathrm{O}, \mathrm{HCO}_{2} \mathrm{Na}$, DIPEA $\downarrow \mathrm{Pd}(\mathrm{OAC})_{2}, \mathrm{LiCl}, \mathrm{DMF}, \mathrm{rt}(76 \%)$

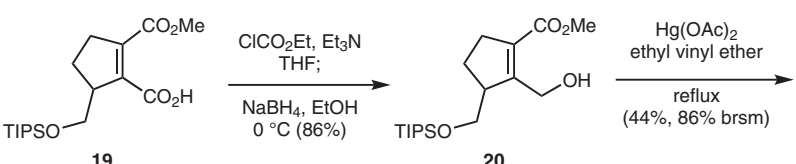

20

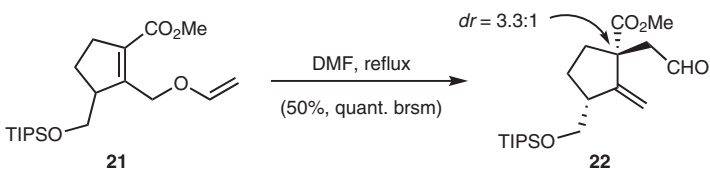

Scheme 2 Preparation of aldehyde $\mathbf{2 2}$

resulted in the formation of lactone $\mathbf{2 3}$. Therefore, $\mathbf{2 2}$ was first converted into the diene $\mathbf{2 5}$, which could be obtained as a single diastereomer about the quaternary center following separation by column chromatography on silica gel. Diene 25 was then dihydroxylated with $\mathrm{OsO}_{4}$ under neutral conditions to afford diol $\mathbf{2 6}$ as a 1:1 mixture of diastereomers in good yield (96\%). The next step of the reaction, the iodoetherification of $\mathbf{2 6}$, required optimization with respect to the solvent. For example, treatment of $\mathbf{2 6}$ with NIS in MeCN afforded the desired product $14(\mathrm{dr}=1: 1)$ in $78 \%$ yield, whereas the use of $\mathrm{CH}_{2} \mathrm{Cl}_{2}$ resulted in the oxidative cleavage of the 1,2-diol to regenerate aldehyde 22 in 51\% yield. For the installation of the unsaturated ester side chain, 14 was treated with the allylstannane $13^{8}$ and AIBN in refluxing benzene to afford alcohol $27(\mathrm{dr}=1: 1)$ in $59 \%$ yield. After iodination of alcohol 27 under Appel's conditions, the tetrahydrofuran ring of iodide $\mathbf{1 2}$ was reductively opened by treatment with $\mathrm{Zn}$ in EtOH at $60{ }^{\circ} \mathrm{C}$ to afford diene $\mathbf{1 1}$ as a single diastereomer in $82 \%$ yield.

The formal synthesis of $\mathbf{2}$ was accomplished by first subjecting 11 to RCM conditions, using the Grubbs secondgeneration catalyst, to construct the seven-membered ring of $\mathbf{2 8}{ }^{13}$ in $86 \%$ yield (Scheme 4 ). The TIPS protecting group was then removed with $\mathrm{TBAF} / \mathrm{AcOH}$, giving alcohol 29 in $54 \%$ yield with $34 \%$ of unreacted 28 remaining. Note that in the absence of $\mathrm{AcOH}$, the reaction was dominated by 1,4addition of the tertiary alcohol to the unsaturated ester. After oxidation to the aldehyde $\mathbf{3 0}$, nucleophilic addition of a methyl group was attempted. Unfortunately, the standard conditions proved fruitless (MeLi, THF, $-78{ }^{\circ} \mathrm{C}$ : decomposition; $\mathrm{MeMgBr}, \mathrm{THF},-78^{\circ} \mathrm{C}$ : no reaction). Trost et al. ${ }^{5}$ report- 
ed that an organocerium reagent served as an excellent nucleophile in a similar transformation. To our delight, treatment of $\mathbf{3 0}$ with $\mathrm{MeCeCl}_{2}{ }^{14}$ followed by Dess-Martin oxidation successfully afforded Trost's intermediate 10, in racemic form, from which pseudolaric acid B (2) has been obtained in six steps, thus completing a formal synthesis of
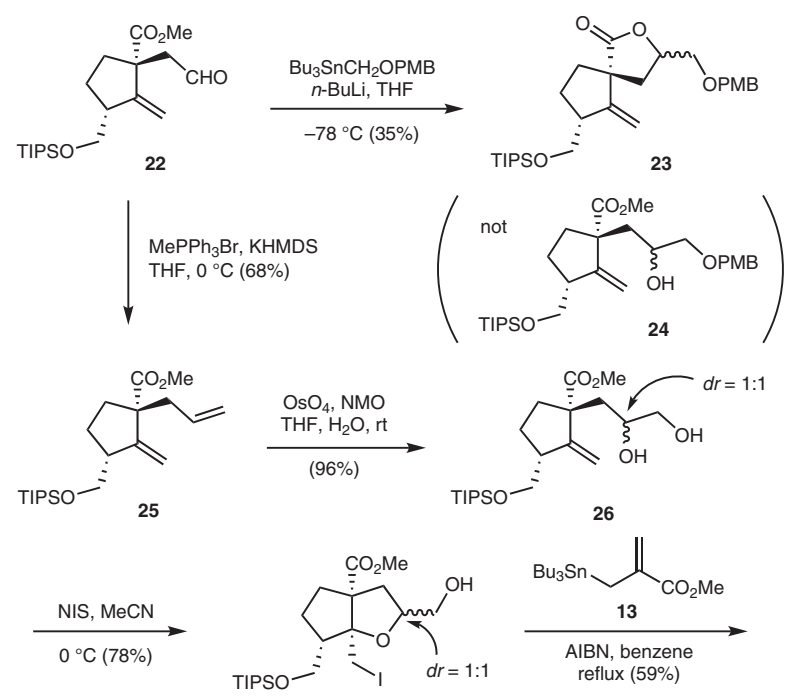

14

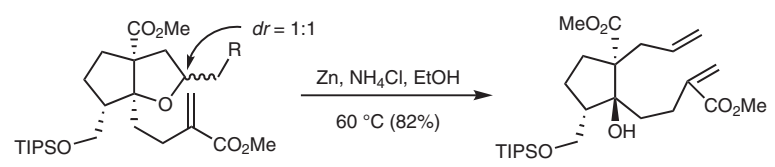

27: $\mathrm{R}=\mathrm{OH} \longrightarrow \mathrm{I}_{2}, \mathrm{PPh}_{3}$, imidazole

12: $\mathrm{R}=1 \longleftarrow$ THF, rt (85\%)

Scheme 3 Preparation of diene $\mathbf{1 1}$
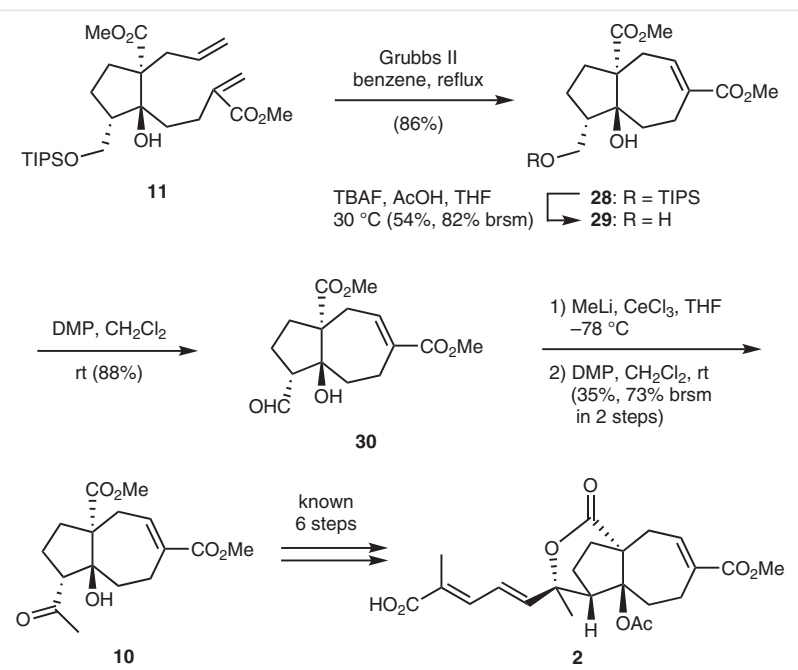

Scheme 4 Formal synthesis of pseudolaric acid B (2)
2. The ${ }^{1} \mathrm{H}$ NMR and ${ }^{13} \mathrm{C}$ NMR spectra of compound 10 prepared in this work agreed with those reported by the Trost group.

In conclusion, we have accomplished a formal synthesis of pseudolaric acid B (2) from the known ketone 15 to Trost's synthetic intermediate $\mathbf{1 0}$ in 17 steps (six more steps are required to obtain $\mathbf{2}$ ). The key elements in the present synthesis include: (1) construction of the vicinal quaternary stereocenters via a Claisen rearrangement $(\mathbf{2 1} \rightarrow$ 22) and stereoselective iodoetherification (26 $\rightarrow \mathbf{1 4})$ and (2) formation of the seven-membered ring through an RCM reaction $(\mathbf{1 1} \rightarrow \mathbf{2 8})$. This current synthesis is more efficient than our previous preparation, ${ }^{6}$ and could expand the opportunities for derivatization of pseudolaric acid $B$ and related compounds as lead anticancer drugs by using $(S)-2-$ (hydroxymethyl)cyclopentan-1-one ${ }^{15}$ as a chiral substrate.

\section{Funding Information}

This work was supported by Grant-in-Aid for Scientific Research (C) from the Japan Society for the Promotion of Science (Grant Number 16K07712).

\section{Acknowledgment}

I am grateful to Professor Masayuki Inoue (The University of Tokyo), Professor Hidenori Watanabe (The University of Tokyo), and Professor Hirosato Takikawa (The University of Tokyo) for their kind and helpful discussions. I thank Professor Shuji Akai (Osaka University), Professor Takeo Kawabata (Kyoto University), Professor Tomohiko Ohwada (The University of Tokyo), Dr. Mitsuaki Ohtani (ITSUU Laboratory), and Dr. Kin-ichi Tadano (ITSUU Laboratory) for their helpful discussions throughout this work. I also thank Mr. Yoshihisa Akamatsu (The University of Tokyo) for the preparation of the starting material 15.

\section{Supporting Information}

Supporting information for this article is available online at https://doi.org/10.1055/s-0039-1690829.

\section{References and Notes}

(1) Chiu, P.; Leung, L. T.; Ko, B. C. B. Nat. Prod. Rep. 2010, 27, 1066.

(2) Mafu, S.; Karunanithi, P. S.; Palazzo, T. A.; Harrod, B. L.; Rodriguez, S. M.; Mollhoff, I. N.; O’Brien, T. E.; Tong, S.; Fiehn, O.; Tantillo, D. J.; Bohlmann, J.; Zerbe, P. Proc. Natl. Acad. Sci. U.S.A. 2017, 114, 974.

(3) Geng, Z.; Chen, B.; Chiu, P. Angew. Chem. Int. Ed. 2006, 45, 6197.

(4) Xu, T.; Li, C.-C.; Yang, Z. Org. Lett. 2011, 13, 2630.

(5) (a) Trost, B. M.; Waser, J.; Meyer, A. J. Am. Chem. Soc. 2007, 129, 14556. (b) Trost, B. M.; Waser, J.; Meyer, A. J. Am. Chem. Soc. 2008, 130, 16424 .

(6) Mori, N.; Mase, C.; Watanabe, H.; Takikawa, H. Tetrahedron Lett. 2018, 59, 2600.

(7) Mittendorf, J.; Kunisch, F.; Matzke, M.; Militzer, H.-C.; Schmidt, A.; Schönfeld, W. Bioorg. Med. Chem. Lett. 2003, 13, 433. 
(8) Baldwin, J. E.; Adlington, R. M.; Birch, D. J.; Crawford, J. A.; Sweeney, J. B. J. Chem. Soc., Chem. Commun. 1986, 1339.

(9) Sano, S.; Matsumoto, T.; Nakao, M. Tetrahedron Lett. 2014, 55 , 4480.

(10) (a) Cook, G. K.; Hornback, W. J.; Jordan, C. L.; McDonald, J. H. III.; Munroe, J. E. J. Org. Chem. 1989, 54, 5828. (b) Chen, X.-T.; Bhattacharya, S. K.; Zhou, B.; Gutteridge, C. E.; Pettus, T. R. R.; Danishefsky, S. J. J. Am. Chem. Soc. 1999, 121, 6563.

(11) Semmelhack, M. F.; Gu, Y.; Ho, D. M. Tetrahedron Lett. 1997, 38, 5583.

(12) Yoshimitsu, T.; Arano, Y.; Kaji, T.; Ino, T.; Nagaoka, H.; Tanaka, T. Heterocycles 2009, 77, 179.

(13) Dimethyl 8a-Hydroxy-1-\{[(triisopropylsilyl)oxy]methyl $\}$ 2,3,4,7,8,8a-hexahydroazulene-3a,6(1H)-dicarboxylate (28) A mixture of diene $11(16.4 \mathrm{mg}, 34.0 \mu \mathrm{mol})$ and the Grubbs second-generation catalyst $(2.9 \mathrm{mg}, 3.42 \mu \mathrm{mol})$ in benzene ( 1.5 $\mathrm{mL}$ ) was refluxed for $5 \mathrm{~h}$, then cooled to rt. The mixture was then concentrated under reduced pressure, and the residue was purified by preparative TLC (hexane-EtOAc, 5:1) to give a colorless oil; yield: $13.3 \mathrm{mg}$ (86\%). IR (film): 3515, 2945, 2866, 1716, 1463, 1238, 1194, 1055, 882, 755, $681 \mathrm{~cm}^{-1} .{ }^{1} \mathrm{H}$ NMR (400 MHz, $\left.\mathrm{CDCl}_{3}\right): \delta=6.96(\mathrm{~m}, 1 \mathrm{H}), 4.00(\mathrm{dd}, J=9.6,6.4 \mathrm{~Hz}, 1 \mathrm{H}), 3.70(\mathrm{~s}, 3$ $\mathrm{H}), 3.59(\mathrm{~m}, 1 \mathrm{H}), 3.58(\mathrm{~s}, 3 \mathrm{H}), 2.85(\mathrm{~m}, 1 \mathrm{H}), 2.76(\mathrm{~m}, 1 \mathrm{H}), 2.58-$ $2.45(\mathrm{~m}, 2 \mathrm{H}), 2.37$ (dt, J = 2.8, $14.0 \mathrm{~Hz}, 1 \mathrm{H}), 2.20(\mathrm{~m}, 1 \mathrm{H}), 2.08-$ $1.85(\mathrm{~m}, 4 \mathrm{H}), 1.23(\mathrm{~m}, 1 \mathrm{H}), 1.12-1.00(\mathrm{~m}, 21 \mathrm{H}) .{ }^{13} \mathrm{C}$ NMR $(100$ $\left.\mathrm{MHz}, \mathrm{CDCl}_{3}\right): \delta=174.64,168.53,140.74,135.51,82.74,65.29$, 58.91, 57.38, 51.88, 51.55, 34.71, 30.39, 29.82, 26.00, 20.35, 18.06, 11.97. HRMS (ESI): $m / z[\mathrm{M}+\mathrm{Na}]^{+}$calcd for $\mathrm{C}_{24} \mathrm{H}_{42} \mathrm{NaO}_{6} \mathrm{Si}$ : 477.2643; found: 477.2637 .

(14) Imamoto, T.; Sugiura, Y.; Takiyama, N. Tetrahedron Lett. 1984, $25,4233$.

(15) Mase, N.; Inoue, A.; Nishio, M.; Takabe, K. Bioorg. Med. Chem. Lett. 2009, 19, 3955. 